\title{
Pathohistological investigation of osteochondral tissue obtained during total knee arthroplasty after osteochondral autologous transfer: a case report
}

\author{
Momoko Tanima-Nagai ${ }^{1}$, Hideto Harada ${ }^{2}$, Tomoki Aoyama ${ }^{3}$, Shoki Yamaguchi ${ }^{4}$, Akira Ito ${ }^{3}$, Junichi Tajino ${ }^{3}$, \\ Hirotaka lijima ${ }^{3}$, Xiankai Zhang ${ }^{3}$, Hiroshi Kuroki ${ }^{3}$ and Masahiko Kobayashi ${ }^{{ }^{*}}$
}

\begin{abstract}
Background: Osteochondral autologous transfer is one of the repair techniques for cartilage defects of knee with promising knee function recovery. There are no reports including histopathological images concerning human osteochondral tissue after osteochondral autologous transfer. This is the first report to present pathohistological findings of transplanted plugs and host tissues extracted from the human body 3 years after osteochondral autologous transfer. This study aimed to explore the cause factor of chronic pain using histological techniques.

Case presentation: A 67-year-old Japanese man presented with adjusted total knee arthroplasty 3 years after osteochondral autologous transfer. Although in pain, arthroscopic assessment was not severe. The specimens which was gained during total knee arthroplasty were investigated in gross and microscopically using immunohistochemical staining technic. Histological examination revealed that the gap between grafted plugs and host osteochondral tissues was filled with fibrous tissue that stained positive for type I collagen. A degenerative change and some neovascularity were observed in the regenerated tissue and host trabecular bone. Furthermore, cysts and bone marrow edema were observed.
\end{abstract}

Conclusion: Our data suggests that the host osteochondral morbidity around grafted plugs might be related to chronical pain and revision surgery.

Keywords: Osteochondral autologous transfer, Pathohistology, Bone marrow edema, Case report

\section{Background}

Osteochondral autologous transfer (OAT) is a repair technique for cartilage defects with good prognosis [1, 2]. There have been numerous reports about clinical outcomes after OAT in humans [1-5], and concerning the histopathology in animal models [6-9]. In contrast, there have been few reports about the histopathology and morbidity of the implanted plugs in humans due to ethical reasons. The purpose of this study was to

\footnotetext{
*Correspondence: masakoba@shimogamo.jp

${ }^{5}$ Department of Orthopedic Surgery, Knee/Shoulder Surgery \& Sports Medicine, Kyoto Shimogamo Hospital, 17 Higashimorigamae-cho, Shimogamo, Sakyo-ku, Kyoto 606-0866, Japan

Full list of author information is available at the end of the article
}

histologically explore the factors leading to chronic pain and revision surgery after OAT. Histological signs would provide information that cannot be obtained by surface observations, which would be helpful in understanding the pathology and in improving the operative technique (Approval an ethics panel no: Kyoto University C186).

\section{Case presentation}

A 67-year-old Japanese man (body mass index, $\mathrm{BMI}=27.7)$ presented to the hospital with right knee pain diagnosed as spontaneous osteonecrosis of the knee and was treated conservatively. Three years later, OAT was performed because of increased pain and cyst formation observed in the subchondral area by magnetic 
resonance imaging. Before OAT, T2-weighted images showed a wide area of low intensity in the right medial femoral condyle (MFC) that reached the bone marrow region (Fig. 1A, B); the Lysholm score was 49/100. The degenerated region measured $25 \times 20 \mathrm{~mm}$ in the weight-bearing area of the MFC and was considered a defect after OAT. A total of three grafts, $10 \mathrm{~mm}$ or $6 \mathrm{~mm}$ in diameter with a depth $16 \mathrm{~mm}$, were harvested from the non-weight-bearing portion of the patella groove and were transferred to the defect area. At 1.5 years after OAT, we confirmed that the International Cartilage Repair Society score was grade II and the Lysholm score was $85 / 100$, although the pain remained a little. Total knee arthroplasty (TKA) was performed 3 years after OAT because of chronic and intense pain. T2-weighted images showed a wide range of osteonecrosis with high
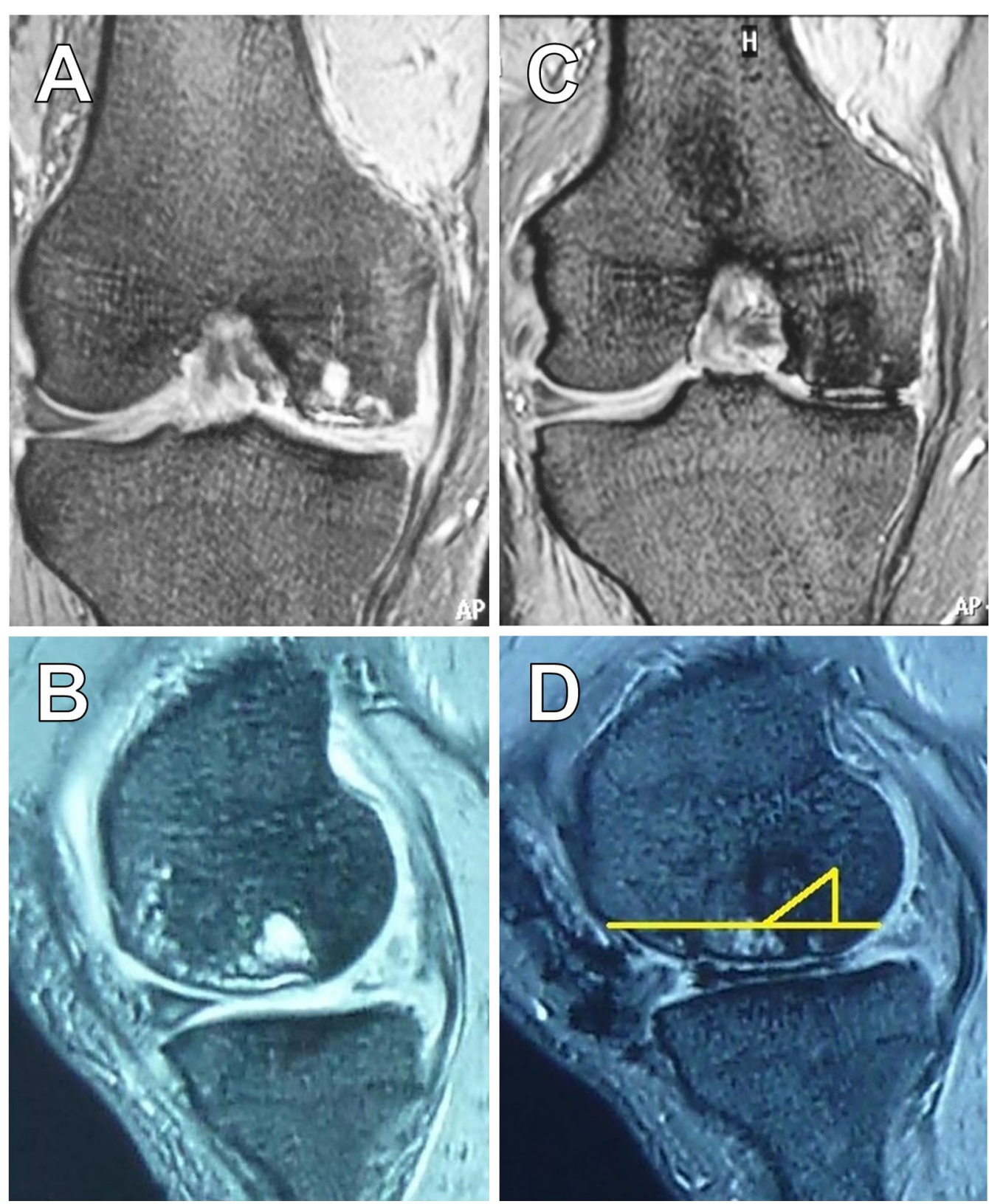

Fig. 1 Magnetic resonance image of pre- and post-osteochondral autologous transfer operation. Low intensity on T2-weighted images of the right medial femoral condyle (A, C coronal plane; B, D sagittal plane). The images were taken before osteochondral autologous transfer $(\mathbf{A}, \mathbf{B})$ and before total knee arthroplasty $(\mathbf{C}, \mathbf{D})$. Yellow lines show the resection line of two parts of the tissue 
signal intensity (Fig. 1C, D). Two parts of osteochondral tissue were isolated so that they could be discarded during TKA; the osteochondral tissue containing implanted plugs (Fig. 2A) and the host trabecular bone located deeper than the engrafted tissue. Isolated tissues were observed macroscopically, fixed, decalcified, and embedded in paraffin. Then, 6- $\mu \mathrm{m}$ sections were stained with hematoxylin-eosin (H-E) and safranin-O (SO). The expressions of type I and type II collagen and vascular endothelial growth factor (VEGF) were analyzed immunohistochemically. We also investigated a comparative control tissue extracted from the normal area of a middle-aged man who underwent TKA.

On macroscopic observation, the tissue of our patient was filled with regenerated tissue among all plugs and host tissue. The surface was almost smooth (Fig. 2A). On microscopic observation, strong SO staining was observed in the engrafted plug, host cartilage, and control tissue (Fig. 2B). The gap between plugs is usually filled with regenerated fibrous tissue with less $\mathrm{SO}$ and type II collagen staining intensity. Instead, type I collagen staining intensity was denser than that for the plug, host cartilage, or control tissue (Fig. 3). There were some cracks in the regenerated fibrous tissue that reached the bone marrow region. Bone marrow edema (BME) or cyst formation within the microvasculature was confirmed mostly in the bone marrow region and these findings were not observed in control tissue (Fig. 2B). Neovascularity indicated by VEGF staining was frequently observed in subchondral area connected to the bone marrow spaces and
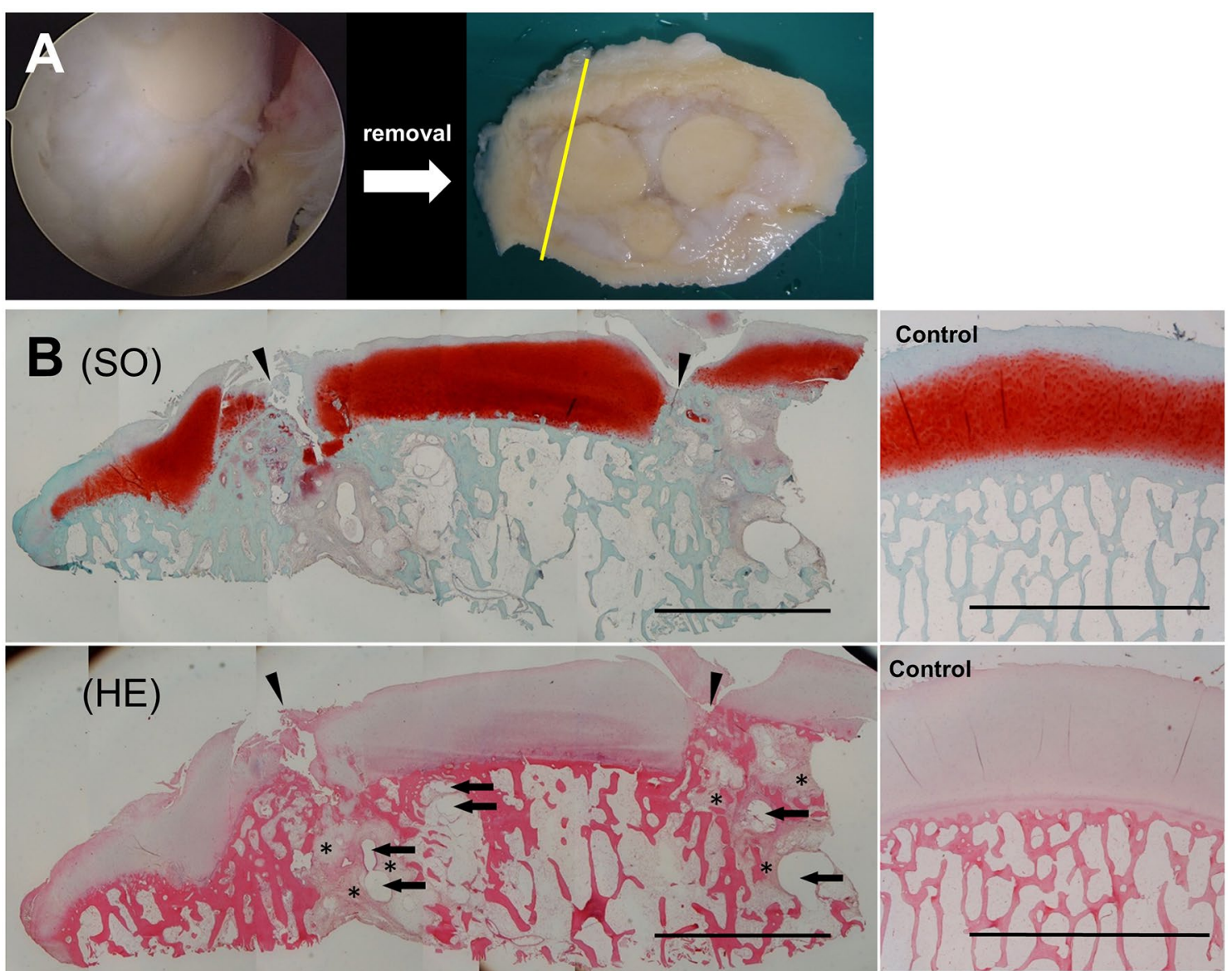

Fig. 2 Arthroscopic images after osteochondral autologous transfer (OAT), and macro and micro observation images of isolated tissue after total knee arthroplasty (TKA). A At 1.5 years after OAT, good prognosis of the transferred grafts was confirmed by arthroscopy (left side). The osteochondral tissue contained inserted plugs that were discarded during TKA. The surface of the tissue was almost smooth (right side). The yellow line indicates the section area of (B). B Histological images with safranin-O staining (upper; SO) and hematoxylin-eosin staining (lower; $\mathrm{H}-\mathrm{E}$ ) show that the cartilage surface was not smooth between the host and plug cartilage. There were some cracks in the regenerated fibrous cartilage that reached bone marrow region. Arrowhead indicates the site of transferred plugs. Asterisk indicates bone marrow edema. Arrows indicate subchondral bone cyst. The control tissue shows the smooth surface of cartilage and strong staining intensity of SO. Scale bars indicate $5 \mathrm{~mm}$ 


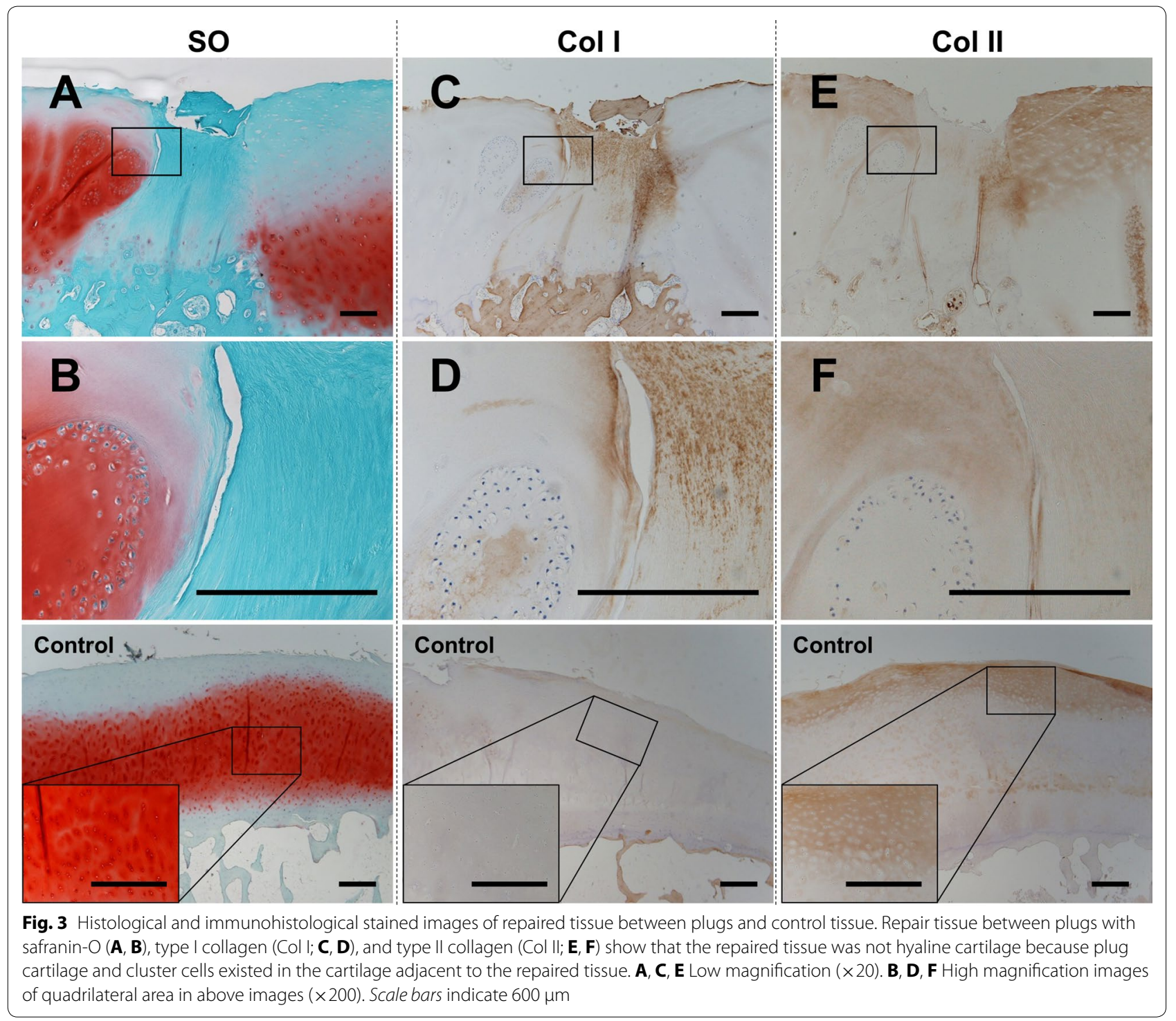

deep subchondral area in the plug and in the host trabecular bone near the BME (Fig. 4).

\section{Discussion}

Some systematic reviews of OAT have reported that risk factors for failure are age $<30$ years, two or more previous surgeries, and defect area $>4-5 \mathrm{~cm}^{2}[1,10]$. Enabling a better healing capability of the young may lead to a better prognosis after OAT [4]. Aging and being overweight are also important risk factors for osteochondral complex degeneration such as osteoarthritis [11]. Being male and overweight (as indicated by BMI) to be the cause of OAT failure in our patient might be speculation; the influence of gender and BMI on OAT outcome is not clear [12].
In this study, we observed osteochondral plugs and host tissue obtained from a patient with spontaneous osteonecrosis diagnosed before OAT surgery. Some cracks reached the subchondral bone in the regenerated fibrocartilage; nevertheless, it was filled with regenerated tissue on macroscopic and arthroscopic observations. Furthermore, BME existed at the subchondral bone and host trabecular bone. A study regarding osteonecrosis reported that osteoporotic bone is more susceptible to microfracture and could be induced by increased or repeated stress in the subchondral bone plate and around the tissue [13]. Microfractures lead to fluid accumulation [14] and intraosseous edema, which cause increased pressure within the marrow cavity and increased vascular 


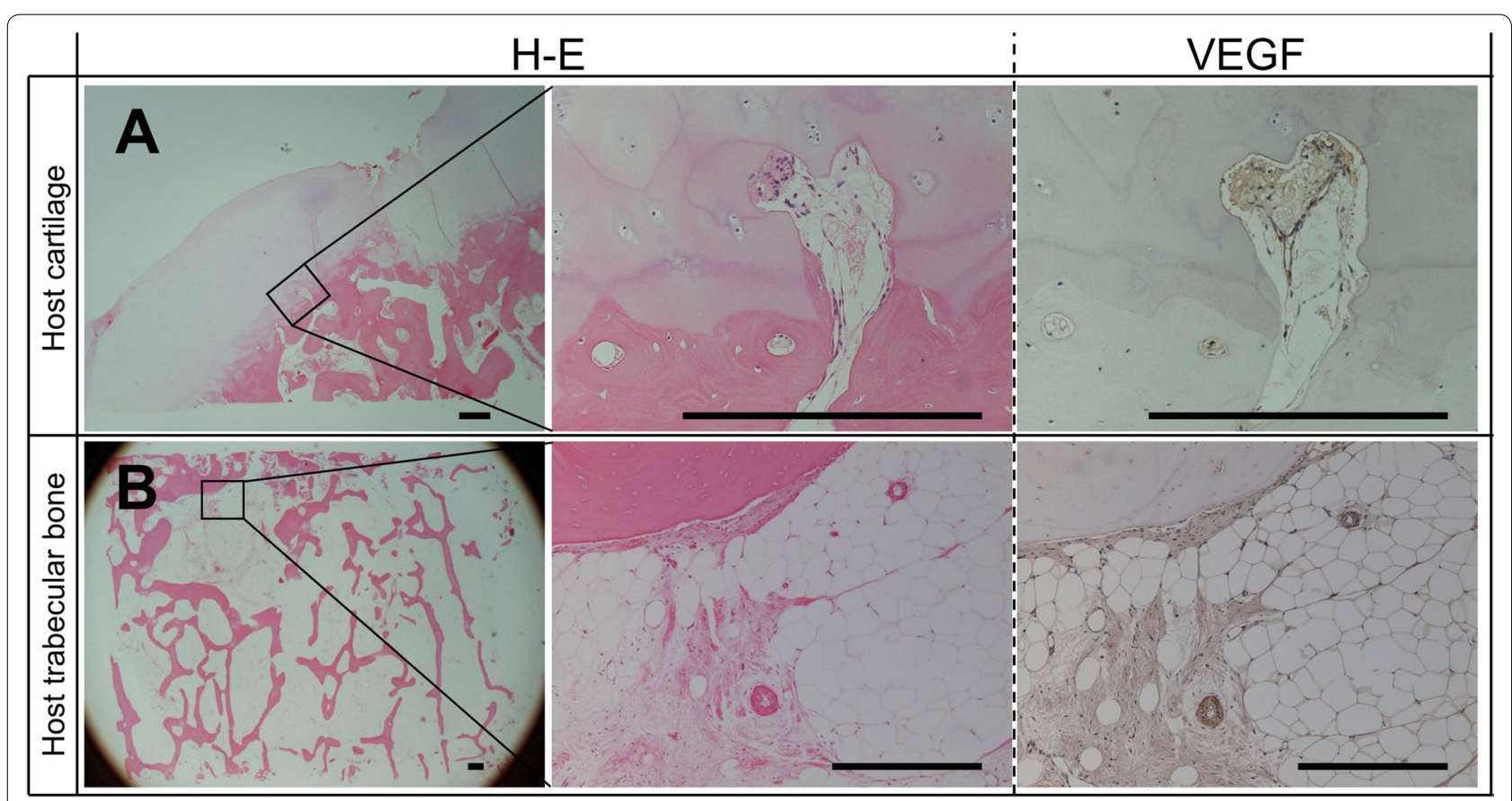

Fig. 4 The results of vascular endothelial growth factor (VEGF) expression and hematoxylin-eosin (H-E) staining at host cartilage and host trabecular bone. VEGF-positive cells and microvascular were often confirmed in the subchondral region connected to the cartilage region (A: upper lane) and in the host trabecular bone region (B: lower lane). Scale bars indicate $200 \mu \mathrm{m}$

compromise of the subchondral bone or worsening of edema, finally resulting in necrosis or cyst [13]. The underlying marrow is rich in nociceptive fibers [15], explaining the close relationship between BME and intraosseous hypertension with pain $[16,17]$. The instability of the morbid region created abnormal mechanical stress, thus producing catabolic pathways in an osteochondral complex $[11,18]$. It is suggested that the existence of a morbid region weakened by mechanical stress in host osteochondral tissue affects cyst and BME formation, leading to the patient's chronic intense pain.

\section{Conclusion}

This study showed the pathohistological findings of transplanted plugs and host tissues extracted from the human body 3 years after OAT. The large extent of the degenerated host area might cause deterioration in the transplanted and regenerative osteochondral tissue, and chronic pain, leading to revision surgery. There is a possibility that removal of the morbid host region and partial bone remodeling could lead to good functional outcomes.

\section{Abbreviations}

OAT: osteochondral autologous transfer; BMI: body mass index; MFC: medial femoral condyle; TKA: total knee arthroplasty; H-E: hematoxylin-eosin; SO: safranin-O; VEGF: vascular endothelial growth factor; BME: bone marrow edema.

\section{Authors' contributions}

MN carried out the all studies and drafted manuscript. HH and MK preformed the surgical treatment. All authors interpreted results. All authors read and approved the final manuscript.

\section{Author details}

${ }^{1}$ Congenital Anomaly Research Center, Kyoto University Graduate School of Medicine, Konoe-cho, Yoshida, Sakyo-ku, Kyoto 606-8501, Japan. ${ }^{2}$ Department of Orthopedic Surgery, Kyoto Katsura Hospital, 17 Hirao-cho, Yamada, Nishikyo-ku, Kyoto 615-8256, Japan. ${ }^{3}$ Department of Physical Therapy, Human Health Sciences, Graduate School of Medicine, Kyoto University, 53, Kawahara-cho, Shogoin, Sakyo-ku, Kyoto 606-8507, Japan. ${ }^{4}$ Department of Physical Therapy, School of Nursing and Rehabilitation Sciences at Odawara, International University of Health and Welfare, 1-2-25 Shiroyama, Odawara, Kanagawa 250-8588, Japan. ${ }^{5}$ Department of Orthopedic Surgery, Knee/Shoulder Surgery \& Sports Medicine, Kyoto Shimogamo Hospital, 17 Higashimorigamae-cho, Shimogamo, Sakyo-ku, Kyoto 606-0866, Japan.

\section{Acknowledgements}

Not applicable.

\section{Competing interests}

The authors declared that they have no competing interests.

\section{Availability of data and materials}

Data sharing not applicable to this article as no datasets were generated or analyzed during the current study. The data and materials used in this article are available by request from the corresponding author (e-mail: masakoba@ shimogamo.jp).

\section{Consent for publication}

Written informed consent was obtained from the patient for publication of this case report and any accompanying images.

Ethics approval and consent to participate Approval an ethics panel no: Kyoto University C186. 


\section{Publisher's Note}

Springer Nature remains neutral with regard to jurisdictional claims in published maps and institutional affiliations.

Received: 20 December 2016 Accepted: 24 May 2017

Published online: 06 June 2017

\section{References}

1. Hangody L, Vásárhelyi G, Hangody LR, Sükösd Z, Tibay G, Bartha L, Bodó G. Autologous osteochondral grafting-technique and long-term results. Injury. 2008;39(Suppl 1):S32-9.

2. Solheim E, Hegna J, Øyen J, Harlem T, Strand T. Results at 10 to 14 years after osteochondral autografting (mosaicplasty) in articular cartilage defects in the knee. Knee. 2013;20:287-90.

3. Levy YD, Görtz S, Pulido PA, McCauley JC, Bugbee WD. Do fresh osteochondral allografts successfully treat femoral condyle lesions? Clin Orthop Relat Res. 2013:471:231-7.

4. De Caro F, Bisicchia S, Amendola A, Ding L. Large fresh osteochondral allografts of the knee: a systematic clinical and basic science review of the literature. Arthroscopy. 2015;31:757-65.

5. Lynch TS, Patel RM, Benedick A, Amin NH, Jones MH, Miniaci A. Systematic review of autogenous osteochondral transplant outcomes. Arthroscopy. 2015;31:746-54

6. Leng P, Ding CR, Zhang HN, Wang YZ. Reconstruct large osteochondral defects of the knee with hIGF-1 gene enhanced Mosaicplasty. Knee. 2012:19:804-11.

7. Lane JG, Healey RM, Chen AC, Sah RL, Amiel D. Can osteochondral grafting be augmented with microfracture in an extended-size lesion of articular cartilage? Am J Sports Med. 2010;38:1316-23.
8. Lane JG, Massie JB, Ball ST, Amiel ME, Chen AC, Bae WC, Sah RL, Amiel D. Follow-up of osteochondral plug transfers in a goat model: a 6-month study. Am J Sports Med. 2004;32:1440-50.

9. Heir S, Årøen A, Løken S, Holme I, Engebretsen L, Reinholt FP. Cartilage repair in the rabbit knee: mosaic plasty resulted in higher degree of tissue filling but affected subchondral bone more than microfracture technique: a blinded, randomized, controlled, long-term follow-up trial in 88 knees. Knee Surg Sports Traumatol Arthrosc. 2012;20:197-209.

10. Bentley G, Bhamra JS, Gikas PD, Skinner JA, Carrington R, Briggs TW. Repair of osteochondral defects in joints - how to achieve success. Injury. 2013:44(Suppl 1):S3-10.

11. Gabay O, Hall DJ, Berenbaum F, Henrotin Y, Sanchez C. Osteoarthritis and obesity: experimental models. Joint Bone Spine. 2008;75:675-9.

12. Bedi A, Feeley BT, Williams RJ 3rd. Management of articular cartilage defects of the knee. J Bone Joint Surg Am. 2010;92:994-1009.

13. Kattapuram TM, Kattapuram SV. Spontaneous osteonecrosis of the knee. Eur J Radiol. 2008;67:42-8.

14. MacDessi SJ, Brophy RH, Bullough PG, Windsor RE, Sculco TP. Subchondra fracture following arthroscopic knee surgery. A series of eight cases. J Bone Joint Surg Am. 2008;90:1007-12.

15. Jacobs CA, Christensen CP, Karthikeyan T. Subchondral bone marrow edema had greater effect on postoperative pain after medial unicompartmental knee arthroplasty than total knee arthroplasty. J Arthroplasty. 2016;31:491-4

16. Arnoldi CC, Lemperg K, Linderholm H. Intraosseous hypertension and pain in the knee. J Bone Joint Surg Br. 1975;57:360-3.

17. Felson DT, Chaisson CE, Hill CL, Totterman SM, Gale ME, Skinner KM, Kazis $\mathrm{L}$, Gale DR. The association of bone marrow lesions with pain in knee osteoarthritis. Ann Intern Med. 2001;134:541-9.

18. Goldring MB, Marcu KB. Cartilage homeostasis in health and rheumatic diseases. Arthritis Res Ther. 2009;11:224.

\section{Submit your next manuscript to BioMed Central and we will help you at every step:}

- We accept pre-submission inquiries

- Our selector tool helps you to find the most relevant journal

- We provide round the clock customer support

- Convenient online submission

- Thorough peer review

- Inclusion in PubMed and all major indexing services

- Maximum visibility for your research

Submit your manuscript at www.biomedcentral.com/submit
() Biomed Central 